\title{
Antioxidant and Antimicrobial Activities of Essential Oils Extracted from Laurus nobilis L. Leaves by Using Solvent-Free Microwave and Hydrodistillation
}

\author{
Sedef Nehir $\mathrm{El}^{1^{*} \text {, Nural Karagozlu}}{ }^{2}$, Sibel Karakaya ${ }^{1}$, Serpil Sahın ${ }^{3}$ \\ ${ }^{1}$ Department of Food Engineering, Faculty of Engineering, Ege University, Izmir, Turkey; ${ }^{2}$ Department of Food Engineering, Faculty \\ of Engineering, Celal Bayar University, Manisa, Turkey; ${ }^{3}$ Department of Food Engineering, Faculty of Engineering, Middle East \\ Technical University, Ankara, Turkey. \\ Email: sedef.el@ege.edu.tr
}

Received December $10^{\text {th }}, 2012$; revised January 20 ${ }^{\text {th }}, 2013$; accepted February $4^{\text {th }}, 2013$

Copyright (C) 2014 Sedef Nehir El et al. This is an open access article distributed under the Creative Commons Attribution License, which permits unrestricted use, distribution, and reproduction in any medium, provided the original work is properly cited. In accordance of the Creative Commons Attribution License all Copyrights (C) 2014 are reserved for SCIRP and the owner of the intellectual property Sedef Nehir El et al. All Copyright (C) 2014 are guarded by law and by SCIRP as a guardian.

\section{ABSTRACT}

In this study, laurel essential oils were obtained by using solvent-free microwave extraction (SFME) and hydrodistillation (HD) methods from Laurus nobilis leaves and determined their antioxidant and antimicrobial activity. Extraction time was reduced by about $43 \%$ in SFME at $622 \mathrm{~W}$ and $67 \%$ in SFME at $249 \mathrm{~W}$ compared to hydrodistillation. Essential oil of laurel was extracted by SFME at $622 \mathrm{~W}(100 \%)$ and $249 \mathrm{~W}(40 \%)$ power levels and HD inhibited oxidation generated by ABTS radical by $93.88 \%, 94.13 \%$ and $92.06 \%$, respectively. Trolox equivalent antioxidant capacities (TEAC) of essential oils were $0.18 \mathrm{mM} / \mathrm{mL}$ oil for SFME at $622 \mathrm{~W}, 1.36 \mathrm{mM} / \mathrm{mL}$ oil for SFME at $249 \mathrm{~W}$ and $2.40 \mathrm{mM} / \mathrm{mL}$ oil for $\mathrm{HD}(\mathrm{p}<0.05)$. Essential oils of $L$. nobilis were extracted by SFME at $100 \%$ and $40 \%$ power levels and $H D$ inhibited linoleic acid peroxidation by $70.57 \%, 63.53 \%$ and $89.18 \%$ respectively. Inhibition effects of laurel essential oils obtained by SFME at different power levels and HD on DPPH radical cation oxidation were not significantly different. The strongest antioxidant activity against DPPH radical was found in the essential oil obtained by SFME at $100 \%$ power level. Essential oils displayed antimicrobial activity against Staphylococcus aureus 6538P, Escherichia coli 0157:H7 and Salmonella typhimurium NRRL E 4463 except for Listeria monocytogenes. The inhibitory effect on Staphylococcus aureus 6538P survival of laurel oil obtained from SFME by using lower power level was found to be lower than that obtained from SFME at $100 \%$ power level and HD $(p<0.05)$.

\section{KEYWORDS}

\section{ABTS; Antimicrobial Activity; Antioxidant Activity; DPPH; Laurel; Laurus nobilis; Solvent-Free Microwave} Extraction; Hydrodistillation

\section{Introduction}

Current research indicates that many chronic diseases, including cardiovascular diseases and at least some types of cancer, are initiated by free radical oxidation of lipids, nucleic acids, or proteins [1]. Therefore, investigating the beneficial effects of dietary antioxidants has been the main goal of many studies. In addition, the need, which is supported by the consumer's concern about natural products, for natural antioxidants and/or antimicrobial

\footnotetext{
${ }^{*}$ Corresponding author.
}

compounds as an alternative to synthetic substances, has been taken much attention in recent years. As a result, interest has focused on different extracts of plants as sources of natural antioxidants since they are rich bioactive organic chemicals and biodegradable to nontoxic products. Herbs and spices are important natural antioxidants. Their antioxidant activity has been attributed to the presence of polar phenolic compounds and essential oils. Particularly, many herbs and spices have been evaluated as sources of natural antioxidants and antimicrobial compounds [2-5]. 
In ancient times, the plant named as "Daphne" was defined as Laurus nobilis by Goodyer in 1655. Leaves of $L$. nobilis are also widely used as a spice, antiseptic, insecticide and stomachic, and are used in the past to treat rheumatism in European folk medicine. L. nobilis, commonly known as bay, sweet bay and laurel, is an evergreen tree native to the Mediterranean region especially in Turkey, Greece, Spain, Italy and France. Laurel leaves have been used as flavoring ingredients in Mediterranean cuisine. They have been traditionally added to meat, fish and poultry meals and also used in food industry as flavor enhancing ingredients in pickle, sauce and canned foods in world and also in Turkey [6,7]. In addition to enhancing flavor, certain spices and their essential oils can prolong the storage life of foods by their antioxidant and/or antimicrobial activities [7-9]. Conforti et al. [10] indicated that beneficial effect of laurel leaves and their essential oils against digestive disorders such as flatulent colic and increasing effect on gastric fluid secretion have been shown in recent studies. Anticonvulsive and antiepileptic activities of the leaf extract have been confirmed. Although, L. nobilis does not have important uses in traditional medicine, recent studies have revealed that L. nobilis leaves and their essential oil could possess some functional activities. Hence, several studies have screened the potential capacity of laurel essential oil as an antimicrobial agent $[11,12]$ and also the antioxidant property of some leaves extracts $[6,3,13]$. Improvements in the production technology of essential oils are quite important to obtain the highest yield and product quality. It is well known that extraction procedure has a great impact on the quality of final product such as extraction efficiency, retention of volatile compounds and bioactive components [14]. New technologies have been developed for obtaining essential oils to minimize the loss of volatile compounds, to improve extraction efficiency and to reduce the process time. Solvent-free microwave extraction (SFME) is one of these new techniques that combine microwave heating with dry distillation at atmospheric pressure for the isolation of essential oils [15].

In this study, antioxidant activity (radical scavenging activity against ABTS and DPPH radicals and inhibition of linoleic acid peroxidation) and antimicrobial activity of essential oils obtained from leaves of $L$. nobilis by using solvent-free microwave (SFME) at different power levels (622 W and $40 \mathrm{~W}$ ) and hydrodistillation (HD) were investigated. Variation in the composition of the essential oils during SFME and hydrodistilation (HD) was also examined.

\section{Materials and Methods}

\subsection{Samples and Chemicals}

Laurel (Laurus nobilis) cultivated in Turkey was kindly provided as dried leaves form by KÜTAŞ Agricultural Products Inc. (Izmir, Turkey). The specimens were collected in November 2006 and September 2007 from location namely Kemalpaşa (Izmir, Aegean region). DPPH (2,2-Diphenyl-1-picrylhydrazyl, D9132), linoleic acid (L1376), phosphate buffer (P4417), hemoglobin (H2500), $\mathrm{FeCl}_{2}$ (372870), methanol were purchased from SigmaAldrich (Germany), ABTS [2-2'-Azino-bis (3-ethylbenzothiazoline-6-sulfonic acid] Diammonium salt (11557) was obtained from Fluka. Ammonium thiocyanate was purchased from Merck.

\subsection{Extraction Methods}

\subsubsection{Solvent-Free Microwave Extraction (SFME)}

A domestic microwave oven with an interior cavity size of $29 \times 37 \times 40 \mathrm{~cm}$ and operating at $2450 \mathrm{MHz}$ was used for SFME (White-Westinghouse, KM90WP Model, Pittsburg, USA). The maximum power of the oven was $622 \mathrm{~W}(100 \%)$ that was determined by IMPI-2L test [16]. Before SFME, $150 \mathrm{~g}$ of laurel leaves were soaked in 700 $\mathrm{ml}$ distilled water at room temperature $\left(25^{\circ} \mathrm{C}\right)$ for $1 \mathrm{~h}$ to hydrate the external layers of the herb. At the end of the soaking period excess water was drained off. The moistened herb was placed in a flat-bottom flask connected to a Clevenger apparatus and SFME procedure was started. Extractions were performed at $622 \mathrm{~W}, 85 \mathrm{~min}(100 \%)$ and $249 \mathrm{~W}, 130 \mathrm{~min}(40 \%)$ conditions. The essential oils were collected in amber colored vials, dehydrated with anhydrous sodium sulfate, capped under nitrogen and kept at $4^{\circ} \mathrm{C}$ until being analyzed.

\subsubsection{Hydrodistillation (HD)}

In conventional hydrodistillation, Clevenger apparatus was used. A hemispherical heater (Thermal Laboratory Equipments, Istanbul, Turkey) with a maximum power of $200 \mathrm{~W}$ was used in the experiments. Distillation was performed using dry leaves to water ratio of 1:10 for 195 min. The essential oil was collected in amber colored vials, dehydrated with anhydrous sodium sulfate, capped under nitrogen and kept at $4^{\circ} \mathrm{C}$ until being analyzed.

\subsection{Essential Oil Composition Analysis}

Identification and quantitative analysis of essential oil components were performed using gas chromatography (Agilent Technologies 6890 N Network GC System, Palo Alto, CA, US) and gas chromatography coupled to mass spectrometry (Agilent Technologies 6890 N Network GC System coupled to Agilent Technologies 5973 Network Mass Selective detector, Palo Alto, CA, US). In order to perform quantative analysis with Flame Ionization Detector (FID) with the Mass Selective Detector (MSD) were placed. 


\subsection{Antioxidant Activity}

\subsubsection{ABTS Free Radical-Scavenging Assay}

ABTS radical scavenging activities of the samples were determined by the method of Re et al. [17]. Briefly, ABTS was dissolved in water to obtain $7 \mathrm{mM}$ concentration. ABTS radical cation was produced by reacting ABTS stock solution with $2.45 \mathrm{mM}$ potassium persulfate (final concentration) and allowing the mixture to stand in the dark at room temperature for 12 - 16 hours before use. For the determination of antioxidant activity, the ABTS radical solution was diluted with ethanol to an absorbance of $0.70( \pm 0.02)$ at $734 \mathrm{~nm}$. After the addition of 1.0 $\mathrm{ml}$ diluted ABTS radical solution to $10 \mu \mathrm{l}$ of the sample, absorbance reading was recorded $5 \mathrm{~min}$ after initial mixing using spectrophotometer (Cary 50 Scan UV-Visible Spectrophotometer, Victoria, Australia). Percent inhibition was calculated by using the following equation:

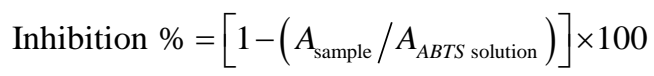

Equation (1) is $A_{\text {sample: }}$ Absorbance reading obtained for the sample, $A_{A B T S \text { solution: }}$ Absorbance reading obtained for ABTS solution.

Trolox equivalent antioxidant capacity (TEAC)

The Trolox equivalent antioxidant capacity assay based on the reaction of ABTS radical with Trolox was performed in order to compare radical scavenging activity of a sample to that of Trolox. The antioxidant activities of the samples were estimated within the range of the dose-response curve of Trolox and expressed as the Trolox equivalent antioxidant capacity. The latter is defined as the concentration of Trolox having the antioxidant capacity equivalent to $1.0 \mathrm{mmol} / \mathrm{l}$ solution of the substance under investigation. In this study, the TEAC values were expressed as $\mu$ mol TEAC $\mu l^{-1}$ sample [18].

\subsubsection{DPPH Free Radical-Scavenging Assay}

The free radical scavenging activity was determined using 1,1-Diphenyl-2-picryl-hydrazyl radical (DPPH) according to Braca et al. [19]. DPPH is a stable free radical, which has an unpaired valence electron at one atom of a nitrogen bridge. In this experiment, $50 \mu \mathrm{L}$ of each extract was added to $950 \mu \mathrm{L}$ of $0.030 \mathrm{mg} / \mathrm{mL}$ methanol solution of DPPH. Then, the mixture was shaken vigorously and left in darkness for 5 min. Finally; the absorbance of the mixture was measured against methanol (blank) at 515 $\mathrm{nm}$ by using spectrophotometer (Cary 50 Scan UV-Visible Spectrophotometer, Victoria, Australia). The DPPH scavenging activity was expressed as the inhibition of the free radical DPPH;

$$
\text { Inhibition }(\%)=1-\left(A_{\text {sample }} / A_{\text {blank }}\right) \times 100
$$

Equation (2) is $A_{\text {sample: }}$ : Absorbance of the sample, $A_{\text {blank: }}$ :
Absorbance of the DPPH.

\subsubsection{Inhibition of the Linoleic Acid Peroxidation} Inhibition effect of the samples on the peroxidation of linoleic acid was determined by the method of Kuo et al. [20]. $10 \mu \mathrm{L}$ of sample, $0.37 \mathrm{~mL}$ of $0.05 \mathrm{M}$ phosphate buffer (pH 7.0) containing $0.05 \%$ Tween 20 and $4 \mathrm{mM}$ of linoleic acid were mixed in a test tube. This mixture equilibrated at $37^{\circ} \mathrm{C}$ for $3 \mathrm{~min}$. The peroxidation of linoleic acid in the mixture was initiated by adding $20 \mu \mathrm{l}$ of $0.035 \%$ hemoglobin prepared in water. Then, mixture incubated at $37^{\circ} \mathrm{C}$ in a shaking water bath under $100 \mathrm{rpm}$ for $10 \mathrm{~min}$. Reaction was stopped by the addition of 5 $\mathrm{mL}$ of $0.6 \% \mathrm{HCl}$ prepared in ethanol. The hydroperoxide formed was determined according to ferric thiocyanate method. Absorbance readings were taken at $480 \mathrm{~nm}$ with a spectrophotometer (Cary 50 Scan UV-Visible Spectrophotometer, Victoria, Australia). Antioxidant activity of the sample was calculated according to the equation below;

$$
\text { Inhibition }(\%)=\left[1-\left(A_{s}-A_{0} / A_{100}-A_{0}\right)\right] \times 100
$$

Equation (3) is $A_{0}=$ Absorbance obtained for reaction mixture that does not contain hemoglobin, $A_{100}=$ Absorbance obtained for reaction mixture that does not contain sample, $A_{s}=$ Absorbance obtained for reaction mixture.

\subsection{Antimicrobial Activity}

Gram-positive and gram-negative bacterial species used in this study were kindly obtained from the culture collection of Microbiology Laboratory in Food Engineering Department of Ege University. The bacteria species include: Listeria monocytogenes Scott A, Staphyloccous aureus 6538P, Esherichia coli O157:H7 and Salmonella typhimurium NRRLE 4463. Trypton Soya Broth (TSB, Oxoid CM 129) was used as media for the development of the strains of pathogen cultures, whereas Plate Count Agar (Oxoid CM 325) was used for the enumeration. Inocula used in the antimicrobial assay were obtained from cultures grown on TSB at $35^{\circ} \mathrm{C}$ for $24 \mathrm{~h}$. Essential oils were sterilized using filtration $0.45 \mu \mathrm{m}$ millipore filters. Antimicrobial tests were then carried out by the disc diffusion method using $100 \mu \mathrm{L}$ of suspension containing $10^{8} \mathrm{CFU} / \mathrm{ml}$ of pathogen bacteria spread on $\mathrm{Nu}-$ trient Agar (NA Oxoid CM0003). The sterilized paperdiscs (5 $\mathrm{mM}$ in diameter) were impregnated aseptically with $10 \mu \mathrm{L}$ of essential oil placed on the inoculated agar. Three discs were placed on each petri plate. Sterilized water was used as a control. Plates were kept at ambient temperature for $1 \mathrm{~h}$ and then incubated at $37^{\circ} \mathrm{C}$ for $24 \mathrm{~h}$. Antimicrobial activity was evaluated by measuring the zone of inhibition against the test organisms [21]. 


\subsection{Statistical Analysis}

All experiments were conducted in triplicate and parallel. Six values for each sample were expressed as mean \pm standard deviation. Statistical analysis was performed using SPSS for Windows (Version 10.0). Analysis of variance (one way ANOVA) was performed, and Tukey HSD multiple range test were used to determine significant differences at $\mathrm{p}<0.05$ [22].

\section{Results and Discussion}

This study is the part of our previous investigation project dealing with extraction of essential oils from some spices using novel technologies and determination of composition, yield and physical properties. Part of our study related composition, yield and physical properties of the essential oil of $L$. nobilis obtained by SFME and HD is presented Table 1 . Maximum yields obtained using SFME at $622 \mathrm{~W}, 249 \mathrm{~W}$ power levels and hydrodistillation method were found to be $0.0235,0.022$ and $0.022 \mathrm{~mL}$ oil/g laurel, respectively. No significant difference was obtained between essential oil yields obtained by SFME and hydrodistillation methods. It was found that the time needed for the complete extraction of essential oil of laurel at $622 \mathrm{~W}$ power was $85 \mathrm{~min}$, while it was $130 \mathrm{~min}$ in $249 \mathrm{~W}$ power. In the case of hydrodistillation, the process time was $195 \mathrm{~min}$. In addition, extraction time was reduced by about $43 \%$ in SFME at 622 $\mathrm{W}$ and $67 \%$ in SFME at $249 \mathrm{~W}$ compared to hydrodistillation. Both of the methods yielded essential oils with the main component 1,8-cineole (630 - $731 \mathrm{mg} / \mathrm{mL}$ oil). The main components of the essential oil of laurel were followed by $\alpha$-terpinyl acetate (90 - $115 \mathrm{mg} / \mathrm{mL}$ oil), sabinene (45 - $55 \mathrm{mg} / \mathrm{mL}$ oil), $\alpha$-pinene (30 - $40 \mathrm{mg} / \mathrm{mL}$ oil), 4-terpineol (35 - $40 \mathrm{mg} / \mathrm{mL}$ oil) and $\beta$-pinene ( $\sim 30$ $\mathrm{mg} / \mathrm{mL}$ oil). It was also found that the essential oil was composed mainly of oxygenated compounds ( $\geq 75 \%)$ while monoterpene hydrocarbons constituted about $\geq 15 \%$ of the essential oil. The oxygenated compounds detected in laurel essential oil were found to be mainly composed of ethers (70\% - 75\%), especially of 1,8-cineole ( 70\%). The rest of the oxygenated constituents of the oil were determined as alcohols, aldehydes, ketones, esters, lactones, and phenols (Table 1).

\subsection{Antioxidant Activity}

Three different methods were used to determine antioxidant activity. These methods are based on the generation of a different radical and inhibition extent of the scavenging by antioxidant compounds which are hydrogen or electron donors $[17,23]$.

\subsubsection{Antioxidant Activity against ABTS Radical}

Generation of the ABTS radical cation forms the basis of one of the spectrophotometric methods that have been applied to the measurement of the total antioxidant activity [17]. Inhibition effects and TEAC values determined for laurel essential oils obtained by SFME methods at different power levels and hydrodistillation on ABTS radical cation oxidation were shown in Table 2. Although ABTS radical scavenging effect of laurel essential oils obtained by two extraction methods was found to be high and similar, TEAC values of these essential oils were significantly different $(\mathrm{p}<0.05)$. Antioxidant activity of essential oil obtained by HD showed the greatest TEAC value which indicated the strongest antioxidant activity. The reason of the similarity between the inhibition effects of SFME and hydrodistillation extracts can be explained by the fact that diluted essential oils are not being used in the inhibition analysis (ABTS decolorization assay). In the ABTS decolorization assay, instead of the dose-response relationship, the inhibition capacity of the intact material against ABTS radical cation oxidation is measured. Therefore, it is not possible to distinguish differences among inhibition values that are above $90 \%$. However, in the TEAC method essential oils are diluted to three different concentrations to obtain three different percentage inhibition values within the range of the doseresponse curve of Trolox and expressed as the TEAC [24]. As far as our literature survey could ascertain, ABTS radical scavenging activity of essential oils obtained from $L$. nobilis have not been reported. There are few reports regarding with antioxidant activities of the extracts obtained from L. nobilis leaves. Kang et al. [2] studied alkyl peroxy radical scavenging activity of the leaves of $L$. nobilis cultivated in Turkey. They reported that only the ethylacetate soluble subfraction obtained from ethanol soluble fraction of $L$. nobilis leaves showed the most potent alkyl peroxy radical scavenging activity. The compound with the highest antioxidant activity isolated from the ethylacetate soluble subfraction was identified as isoquercetrin. Ünver et al. [25] reported that antioxidant activity of $L$. nobilis extract calculated as TEAC value against ABTS radical was $1.001 \mathrm{mmol} \mathrm{TE} / \mathrm{g}$ extract. In the study of Shan et al. [26] ABTS radical scavenging activity of methanolic extract of $L$. nobilis was found to be $34.3 \mathrm{mmol}$ Trolox/100g DW. Comparison of our result with the data reported by Ünver et al. [25] and Shan et al. [26] could not be possible since the extraction methods and sample characteristics used in these studies were different.

\subsubsection{Antioxidant Activity against DPPH Radical} DPPH is a stable nitrogen-centered free radical, the color of which changes from violet to yellow upon reduction by either the process of hydrogen- or electron-donation. Substances, which are able to perform this reaction, can be considered as antioxidants and therefore radical sca- 
Antioxidant and Antimicrobial Activities of Essential Oils Extracted from Laurus nobilis L.

Leaves by Using Solvent-Free Microwave and Hydrodistillation

Table 1. Composition of $\boldsymbol{L}$. nobilis essential oils obtained from SFME and HD.

\begin{tabular}{|c|c|c|c|c|}
\hline & & \multicolumn{3}{|c|}{ Concentration (mg/ml) } \\
\hline & & Hydrodistillation & SFME-622 W & SFME-249 W \\
\hline & Compounds & $195 \min$ & $85 \min$ & $130 \mathrm{~min}$ \\
\hline 1 & $\alpha$-thujene & 3.45 & 3.29 & 2.67 \\
\hline 2 & $\alpha$-pinene & 38.98 & 38.89 & 32.62 \\
\hline 3 & camphene & 2.87 & 2.92 & 2.43 \\
\hline 4 & sabinene & 47.03 & 53.45 & 46.69 \\
\hline 5 & $\beta$-pinene & 32.35 & 33.28 & 30.21 \\
\hline 6 & $\alpha$-phellandrene & 1.58 & - & 0.90 \\
\hline 7 & $\alpha$-terpinene & 4.92 & 4.46 & 4.25 \\
\hline 9 & limonene & - & - & 8.17 \\
\hline 10 & 1,8-cineola & 630.24 & 731.75 & 653.05 \\
\hline 11 & $\gamma$-terpinene & 8.89 & 8.18 & 8.74 \\
\hline 12 & terpinolene & 2.92 & 2.30 & 2.60 \\
\hline 13 & linalool & 2.40 & 2.17 & 2.48 \\
\hline 14 & pinocarveol/trans-pinocarveol & 9.83 & 11.30 & 12.07 \\
\hline 15 & camphor & 0.89 & - & 1.03 \\
\hline 16 & sabina ketone & 3.67 & 4.40 & 5.72 \\
\hline 17 & pinocarvone & 6.30 & 8.03 & 8.03 \\
\hline 20 & $\alpha$-terpineol & 2.22 & 2.90 & 3.06 \\
\hline 21 & myrtenal & 10.09 & 12.50 & 12.49 \\
\hline 22 & cuminal & 3.06 & 3.43 & 3.50 \\
\hline 23 & carvone & 2.75 & 3.01 & 3.33 \\
\hline 24 & bornyl acetate & 4.54 & 4.83 & 4.37 \\
\hline 25 & cumic alcohol & 1.62 & 2.64 & 2.47 \\
\hline 26 & pseudolimonene & 7.14 & 8.02 & 8.64 \\
\hline 27 & $\alpha$-terpynil acetate & 90.28 & 107.30 & 115.32 \\
\hline 28 & eugenol & 12.15 & 16.36 & 17.32 \\
\hline 29 & $\beta$-elemene & - & 1.31 & 1.93 \\
\hline 30 & methyl eugenol & 12.08 & 14.76 & 14.93 \\
\hline 31 & $\beta$-caryophyllene trans/cis-methyl & - & 2.28 & 3.10 \\
\hline 32 & isoeugenol & - & 1.63 & 1.00 \\
\hline 33 & $\beta$-eudesmol dehydrocostuslacto & 4.04 & 4.84 & 3.89 \\
\hline 34 & ne (?) & 0.97 & 5.15 & 1.83 \\
\hline \multirow[t]{2}{*}{35} & eremanthin & - & 3.05 & - \\
\hline & $\%$ total & 91.26 & 88.69 & 88.75 \\
\hline
\end{tabular}

SFME = Solvent-free microwave extraction; HD = Hyrodistillation. 
Table 2. Scavenging effect of $L$. nobilis essential oils obtained from SFME and HD on ABTS and DPPH radicals and linoleic acid peroxidation ${ }^{1,2}$.

\begin{tabular}{|c|c|c|c|c|}
\hline \multirow{2}{*}{ Extraction methods } & \multicolumn{2}{|c|}{ ABTS } & \multirow{2}{*}{$\frac{\mathrm{DPPH}}{\text { Inhibition \% }}$} & \multirow{2}{*}{$\begin{array}{c}\text { Linoleic acid peroxidation } \\
\text { Inhibition } \%\end{array}$} \\
\hline & Inhibition \% & TEAC $\mathrm{mM} / \mathrm{ml}$ oil & & \\
\hline SFME (at $100 \%$ power level) & $93.9 \pm 1.12^{\mathrm{a}}$ & $0.18 \pm 0.012^{\mathrm{a}}$ & $91.1 \pm 1.62^{\mathrm{a}}$ & $70.6 \pm 5.89^{a}$ \\
\hline SFME (at $40 \%$ power level) & $94.1 \pm 3.15^{\mathrm{a}}$ & $1.4 \pm 0.03^{b}$ & $76.3 \pm 14.82^{\mathrm{a}}$ & $63.5 \pm 17.8^{\mathrm{a}}$ \\
\hline HD & $92.1 \pm 2.31^{\mathrm{a}}$ & $2.4 \pm 0.09^{c}$ & $83.3 \pm 6.63^{\mathrm{a}}$ & $89.2 \pm 1.02^{\mathrm{a}}$ \\
\hline
\end{tabular}

${ }^{1}$ Results are given as mean \pm standard deviation $(\mathrm{n}=6)$; ${ }^{2}$ Different superscript denotes statistically significant differences $(p<0.05)$ among data in the same column; TEAC $=$ Trolox equivalent antioxidant capacity, SFME $=$ Solvent-free microwave extraction.

vengers [27]. Inhibition effects of laurel essential oils obtained by SFME at different power levels and HD on DPPH radical cation oxidation were shown in Table 2. No significant difference was found for the essential oils obtained by SFME (at 100\% and 40\% power level) and HD. Hinneburg et al. [28] studied antioxidant activity of hydrodistilled extracts of nine herbs and spices. They reported that extracts obtained from basil and laurel displayed the highest antioxidant activity in the ABTS and DPPH radical scavenging assays than the iron-chelating assay. Antioxidant activities of herbs and spices have been mainly attributed to phenolic compounds and essential oils they contain [2]. It was reported that essential oil of laurel has more than 40 components. The major components of laurel essential oil that determine the specific odor of the plant and its essential oil are reported to be as 4-terpineol, alfa-terpenyl acetate, and methyleugenol [3]. Misharina and Polshkov [29] reported that, probably, terpinenes and other compounds (having various functional groups and differing in redox properties) stabilize the system of laurel essential oil and inhibit the oxidation of reactive substances (e.g., monoterpene hydrocarbons and trans-anethol). They also reported that the composition of volatile compounds in laurel leaves largely depends on the age of the plants, their origin, and the time of collection of the leaves, and the duration and conditions of storage. In our project, compositions of laurel essential oil obtained from both SFME and HD extraction methods were found to be similar. Main components of laurel essential oil are 1,8-cineole (630 - 730 $\mathrm{mg} / \mathrm{mL}$ oil), $\alpha$-terpinyl acetate $(90-115 \mathrm{mg} / \mathrm{mL}$ oil), sabinene (45 - $55 \mathrm{mg} / \mathrm{mL}$ oil), $\alpha$-pinene (30 - $40 \mathrm{mg} / \mathrm{mL}$ oil), 4-terpineol (35 - $40 \mathrm{mg} / \mathrm{mL}$ oil) and $\beta$-pinene ( 30 $\mathrm{mg} / \mathrm{mL}$ oil) [15]. Politeo et al. [30] evaluated the antioxidant activity of laurel volatile aglycones and compared its antioxidant activity with the antioxidant activity of laurel essential oil and well known synthetic antioxidant butylated hydroxytoluene (BHT) by using DPPH radical scavenging method and ferric reducing/antioxidant power assay (FRAP). They found that the decrease in the concentration of volatile aglycones caused a reduction in the antioxidant activity. Among the identified compounds in the volatile aglycone fraction and the essential oil of laurel, eugenol ( $0.3 \%$ and $2.5 \%$ respectively) and methyl eugenol (10\% in essential oil) considered as the main contributors to the antioxidant activity. In our previous investigation project eugenol content of the essential oils obtained by SFME at $100 \%$ and $40 \%$ power levels and HD were $16.36 \mathrm{mg} / \mathrm{mL}$ oil (1.41 of the identified compounds), $17.32 \mathrm{mg} / \mathrm{mL}$ oil (1.59\% of the identified compounds) and $12.153 \mathrm{mg} / \mathrm{mL}$ oil $(1.21 \%$ of the identified compounds) respectively. Methyl eugenol content of the essential oils were $14.757 \mathrm{mg} / \mathrm{ml}$ for SFME at $100 \%$ power level, $14.933 \mathrm{mg} / \mathrm{ml}$ for SFME at $40 \%$ power level and $12.075 \mathrm{mg} / \mathrm{ml}$ for $\mathrm{HD}$ which representing $1.27 \%, 1.37 \%$ and $1.20 \%$ of the identified compounds in the oil, respectively [31].

\subsubsection{Inhibition of the Linoleic Acid Peroxidation}

Lipid peroxidation is an early event in the deterioration of food quality during processing and/or storage and in the development of degenerative diseases (e.g., cardiovascular diseases and age-related disorders).

The most important reaction in lipid peroxidation is the autoxidation of unsaturated fatty acids, which is known to proceed by a radical chain reaction [3]. Essential oils of $L$. nobilis obtained from SFME at two power levels and HD were analyzed in order to determine their inhibitory effects on the linoleic acid peroxidation. Essential oils of $L$. nobilis extracted by SFME at $100 \%$ power level and 40\% power level inhibited linoleic acid peroxidation by the percentages of $70.57 \pm 5.89$ and $63.53 \pm 17.8$ respectively ( $p>0.05$ ) (Table 2). Although essential oil obtained by HD showed greater inhibitory effect on the linoleic acid peroxidation $(89.18 \% \pm 1.02 \%)$ than those obtained by SFME, this difference was not found to be statistically significant. Hinneburg et al. [28] reported that $1 \mathrm{~g}$ of laurel extract obtained by hydrodistillation was as effective as about $212 \mathrm{mg}$ of Trolox in the prevention of lipid peroxidation. To determine antioxidant activity of methanolic extracts of laurel leaves, Simic et al. [12] used the lipid peroxidation inhibition in liposomes induced by $\mathrm{Fe}^{+2}$ /ascorbate system. Maximum antioxidant activity obtained for defatted and crude ex- 
tracts were reported as $68.4 \%$ and $64.6 \%$, respectively.

\subsection{Antimicrobial Activity}

Two gram-positive (Staphylococcus aureus 6538P and Listeria monocytogenes Scott-A) and two gram-negative bacteria (Escherichia coli O157:H7, Salmonella typhimurium NRRL E 4463) were used the possible antimicrobial activity of HD and SFME extracts of laurel leaves. Laurel essential oils obtained from HD and SFME at $100 \%$ and $40 \%$ power levels inhibited the survival of all microorganisms studied except Listeria monocytogenes Scott-A. Laurel essential oils obtained by SFME at $100 \%$ power level and HD against $S$. aureus 6538P inhibition zones (4.5 mM) (Table 3). However, inhibition effect of laurel oil obtained by SFME at $40 \% \mathrm{~W}(3.5 \mathrm{mM})$ was weaker than other oils obtained from SFME at 100\% power level and HD ( $<$ 0.05) (Table 2). Simic et al. [32] found a relationship between the high presence of 1,8 cineole and sabinene in L. nobilis oil and moderate-high antifungal activity of this oil. Derwich et al. [33] reported that Staphlococcus aureus was the most sensitive strain among the bacteria tested (Staphylococcus intermedius and Klebsiella pneumoniae) to the oil of Lauris nobilis the strongest inhibition zone of $13 \mathrm{~mm}$. Although inhibition zone that we determined for $S$. aureus 6538P was smaller $(4.5 \mathrm{~mm})$ than that of reported by Derwich et al. [33]. S. aureus was the most sensitive strain to the essential oils obtained from SFME at 100\% power level and HD. It was reported that essential oils have greater antimicrobial activity on gram-positive bacteria than gramnegative. This result explained the higher resistance among gram-negative bacteria than gram-positive bacteria could be due to the differences in the cell membranes of these bacterial groups. Indeed, the external membrane of gram-negative bacteria renders their surfaces highly hydrophobic, whereas the lipophilic ends of the lipoteichoic acids of the cell membrane of gram-positive bacteria may facilitate penetration by hydrophobic compounds [34]. However, all extracts we studied did not display any inhibitory effect on the survival of Listeria monocy- togenes. Muñoz et al. [35] evaluated antimicrobial properties of oregano, rosemary and laurel extracts obtained by supercritical fluid extraction on the growth and viability of Listeria monocytogenes CECT 4032 in laboratory medium and broccoli juice at $30^{\circ} \mathrm{C}$ and $8{ }^{\circ} \mathrm{C}$. They found that rosemary and oregano extracts reduced the counts of L. monocytogenes CECT 4032 below the detection limits (ca $1.0 \mathrm{lo} \mathrm{cfu} / \mathrm{mL}$ ) after $4 \mathrm{~h}$ at $30^{\circ} \mathrm{C}$ in laboratory medium. However, significant reductions in growth rate and increase in lag phase of $L$. monocytogenes were observed in the presence of some of the laurel and oregano extracts at both temperatures. Effect of extraction methods on the survival of Salmonella typhimurium NRRL E 4463 was the same $(2.5 \mathrm{mM})$. Similarly, antimicrobial activity of essential oils obtained from SFME at two power levels and HD against Escherichia coli O157:H7 were not found to be significantly different. Antimicrobial activities of spices, their active components and their essential oils on the growth of pathogenic bacteria and other microorganisms leading to spoilage of foods, have been studied intensively in recent years. It is well known that, sage, anise, daphne, mustard, black pepper, thyme, lavender, laurel, oregano, fennel, cumin, mint, garlic and cinnamon have inhibitory effects on the survival of bacteria such as Bacillus cereus, B. subtilis, Clostridium botulinum, Escherichia coli, Staphylococcus aureus, Listeria monocytogenes and several fungi [36-38]. Sağdıç et al. [36] and Özcan and Erkmen [39] studied antimicrobial activity of spices including cumin, Helichrysum compactum Boiss. (HC), myrtle, oregano, sage, laurel and thyme against $E$. coli O157:H7. Both studies data showed that inhibitory activity of laurel on the growth of $E$. coli O157:H7 were not determined. Sağdıç and Özcan [40] reported that hydrosols of laurel showed no antimicrobial activity against Bacillus amyloliquefaciens ATCC 23842, Bacillus brevis FMC 3, Bacillus cereus FMC 19, Bacillus subtilis var. niger ATCC 10, Enterobacter aerogenes CCM 2531, Escherichia coli ATCC 25922, Escherichia coli O157:H7 ATCC 33150, Klebsiella pneumoniae FMC 5, Proteus vulgaris FMC 1, Salmonella enteritidis,

Table 3. Antimicrobial activity of $L$. nobilis essential oils obtained from SFME and HD'

\begin{tabular}{|c|c|c|c|c|}
\hline & \multirow[b]{3}{*}{ Control } & \multicolumn{3}{|c|}{ Diameter of the zones of inhibition in $\mathrm{mm}$ ( $5 \mathrm{~mm}$ disc) } \\
\hline & & \multicolumn{2}{|c|}{ SFME } & \multirow{2}{*}{ HD } \\
\hline & & $100 \%(622 \mathrm{~W})$ & $40 \%(249 \mathrm{~W})$ & \\
\hline Listeria monocytogenes Scott-A & $0^{\mathrm{a}}$ & $0^{\mathrm{a}}$ & $0^{\mathrm{a}}$ & $0^{\mathrm{a}}$ \\
\hline S. aureus $6538 \mathrm{P}$ & $0^{\mathrm{a}}$ & $4.5^{\mathrm{b}}$ & $3.5^{\mathrm{c}}$ & $4.5^{\mathrm{b}}$ \\
\hline S. typhimurium NRRL E4463 & $0^{\mathrm{a}}$ & $2.5^{\mathrm{b}}$ & $2.5^{\mathrm{b}}$ & $2.5^{\mathrm{b}}$ \\
\hline E. coli $\mathrm{O} 157: \mathrm{H7}$ & $0^{\mathrm{a}}$ & $3.5^{\mathrm{b}}$ & $3.5^{\mathrm{b}}$ & $3.5^{\mathrm{b}}$ \\
\hline
\end{tabular}

${ }^{1}$ Different superscript denotes statistically significant differences $(p<0.05)$ among data in the same row. 
Salmonella gallinarum, Salmonella typhimurium, Staphlococcus aureus ATCC 2392, Staphylococcus aureus ATCC 28213 and Yersinia enterocolitica ATCC 1501. Dadalıoglu and Evrendilek [38] reported that oregano, bay laurel, spanish lavender and fennel cultivated in Turkey exhibited inhibitory activity on Escherichia coli O157:H7, Listeria monocytogenes, Salmonella typhimurium and Staphylococcus aureus at 5 - 80 ppb concentration.

\section{Conclusion}

In conclusion, no significant differences were obtained in the maximum essential oil yields obtained by SFME and hydrodistillation, but SFME can be preferred to HD since extraction time was reduced considerably. In the future, comparison of the two methods by using the same extraction time would be more convincing. Antioxidant activity of essential oil obtained by HD showed the greatest TEAC value which indicated the strongest antioxidant activity. Inhibition effects of laurel essential oils obtained by SFME at different power levels and HD on DPPH radical cation oxidation were not significantly different. Essential oil obtained from L. nobilis leaves by SFME and HD showed similar acted as antimicrobial agents against microorganisms studied, except for Listeria monocytogenes Scott-A. This study revealed that laurel essential oil might be used for the prevention of deterioration of foods during storage. There has been growing tendency to possible use of natural antioxidants instead of synthetic antioxidants, which are widely used in food industry. Interest in the role of antioxidants in human health has encouraged research in food science to determine how their content and activity can be maintained or even improved through extraction methods and processing technologies. For this reason, efforts have been concentrated on the use of natural extracts especially essential oils such as those obtained from plants, herbals and spices. The antimicrobial activity of essential oils has taken great importance as an alternative for synthetic antimicrobials because they are a part of human diet and their biodegradabilities suggest low toxic residue problems.

\section{Acknowledgements}

The TUBITAK; The Scientific and Technologic Research Council of Turkey (Grant No. TOVAG 104 O 265) financially supported this study.

\section{REFERENCES}

[1] L. Langseth, "Oxidants, Antioxidants, and Disease Prevention,” ILSI Europe Press, 2000.

[2] H. W. Kang, K. W. Yu, W. J. Jun, I. S. Cahng, S. B. Han, H. Y. Kim and H. Y. Cho, "Isolation and Characterization of Alkyl Peroxy Radical Scavenging Compound from Leaves of Laurus nobilis," Chemical and Pharmaceutical Bulletin, Vol. 25, No. 1, 2002, pp. 102-108.

[3] S. Santoyo, R. Lloría, L. Jaime, E. Ibañez, F. J. Señoráns and G. Reglero, "Supercritical Fluid Extraction of Antioxidant and Antimicrobial Compounds from Laurus nobilis L. Chemical and Functional Characterization,” European Food Research and Technology, Vol. 222, No. 5, 2006, pp. 565-571. http://dx.doi.org/10.1007/s00217-005-0027-9

[4] M. Elmastas, İ. Gülçin, Ö. Işıldak, Ö. İ. Küfrevioğlu, K. İbaoğlu and H. Y. Aboul-Enein, "Antioxidant Capacity of Bay (Laurus nobilis L.) Leave Extracts,” Journal of the Iranian Chemical Society, Vol. 3, No. 3, 2006, pp. 258266.

[5] P. Pillai and K. Ramaswamy, "Effect of Naturally Occuring Antimicrobials and Chemical Preservatives on the Growth of Aspercillus parasiticus,” Journal of Food Science and Technology, 2011.

[6] M. Škerget, P. Kotnik, M. Hadolin, A. R. Hraš, M. Simonic and Z. Knez, "Phenols Proanthocyanidins Flavones and Flavonoids in Some Plant Materials and Their Antioxidant Activities," Food Chemistry, Vol. 89, No. 2, 2005, pp. 191-198.

http://dx.doi.org/10.1016/j.foodchem.2004.02.025

[7] H. Yalçın, M. Akın, M. Şanda and A. Çakır, "Gas Chromatography/Mass Spectrometry Analysis of Laurus nobilis Essential Oil Composition of Northern Cyprus,” Journal of Medicinal Food, Vol. 10, No. 4, 2007, pp. 715-719. http://dx.doi.org/10.1089/jmf.2007.404

[8] M. Polovka and M. Suhaj, "Detection of Caraway and Bay Leaves İrradiation Based on Their Extracts' Antioxidant Properties Evaluation,” Food Chemistry, Vol. 119, No. 1, 2010, pp. 391-401. http://dx.doi.org/10.1016/j.foodchem.2009.07.005

[9] M. Karpiǹska-Tymoszezyk, "The Effects of Oil Soluble Rosemary Extract, Sodium Erythorbate and a Mixture of Oil-Soluble Rosemary Extract and Sodium Erythorbate on the Quality of Cooked Meatballs," Journal of Food Science and Technology, Vol. 50, No. 3, 2013, pp. 443454. http://dx.doi.org/10.1007/s13197-011-0359-3

[10] F. Conforti, G. Statti, D. Uzunov and F. Menichini, "Comparative Chemical Composition and Antioxidant Activities of Wild and Cultivated Laurus nobilis L. Leaves and Foeniculum vulgare subsp. piperitum (Ucria) Coutinho Seeds,” Biological \& Pharmaceutical Bulletin, Vol. 29, 2006, pp. 2056-2064.

http://dx.doi.org/10.1248/bpb.29.2056

[11] S. A. Burt and R. D. Reinders, "Antibacterial Activity of Selected Plant Essential Oils against Escherichia coli O157:H7," Letters in Applied Microbiology, Vol. 36, No. 3, 2003, pp. 162-167. http://dx.doi.org/10.1046/j.1472-765X.2003.01285.x

[12] M. Simic, N. Kundakovic and N. Kovacevic, "Preliminary Assay on the Antioxidative Activity of Laurus nobilis Extracts," Fitoterapia, Vol. 74, No. 6, 2003, pp. 613616. http://dx.doi.org/10.1016/S0367-326X(03)00143-6

[13] A. Ferreira, C. Proenç, M. L. M. Serralheiro and M. E. M. 
Araújo, "The in Vitro Screening for Acetylcholinesterase Inhibition and Antioxidant Activity of Medicinal Plants from Portugal,” Journal of Ethnopharmacology, Vol. 108, No. 1, 2006, pp. 31-37. http://dx.doi.org/10.1016/j.jep.2006.04.010

[14] M. A. Ferhat, N. Tigrine-Kordjani, S. Chemat, B. Y. Meklati and F. Chemat, "Rapid Extraction of Volatile Compounds Using a New Simultaneous Microwave Distillation: Solvent Extraction Device,” Chromatographia, Vol. 65, No. 3-4, 2007, pp. 217-222. http://dx.doi.org/10.1365/s10337-006-0130-5

[15] B. Bayramoglu, S. Sahin and G. Sumnu, "Extraction of Essential Oil from Laurel Leaves by Using Microwaves," Separation Science and Technology, Vol. 44, No. 3, 2009, pp. 722-733. http://dx.doi.org/10.1080/01496390802437271

[16] C. Buffler, "Microwave Cooking and Processing: Engineering Fundamentals for the Food Scientists,” AVI Book Press, New York, 1993. http://dx.doi.org/10.1007/978-1-4757-5833-7

[17] R. Re, N. Pelegrini, A. Proteggente, A. Pannala, M. Yang and C. Rice-Evans, "Antioxidant Activity Applying an Improved ABTS Radical Cation Decolorization Assay," Free Radical Biology and Medicine, Vol. 26, No. 9-10, 1999, pp. 1231-1237. http://dx.doi.org/10.1016/S0891-5849(98)00315-3

[18] N. J. Miller, C. A. Rice-Evans, M. J. Davies, V. Gopinathan and A. Milner, "A Novel Method for Measuring Antioxidant Capacity and Its Application to Monitoring the Antioxidant Status in Premature Neonates," Clinical Science, Vol. 84, No. 4, 1993, pp. 407-412.

[19] A. Braca, N. D. Tommasi, L. D. Bari, C. Pizza, M. Politi and I. Morelli, "Antioxidant Principles from Bauhinia Terapotensis,” Journal of Natural Products, Vol. 64, No. 7, 2001, pp. 892-895. http://dx.doi.org/10.1021/np0100845

[20] J. M. Kuo, D. B. Yeh and B. S. Pan, "Rapid Photometric Assay Evaluating Antioxidative Activity in Edible Plant Material," Journal of Agricultural and Food Chemistry, Vol. 47, No. 8, 1999, pp. 3206-3209. http://dx.doi.org/10.1021/jf9813510

[21] M. Güllüce, F. Sahin, M. Sokmen, H. Ozer, D. Daferera, A. Sokmen, M. Polissiou, A. Adiguzel and H. Ozkan, "Antimicrobial and Antioxidant Properties of the Essential Oils and Methanol Extract from Mentha longifolia L. ssp Longifolia,” Food Chemistry, Vol. 103, No. 4, 2007, pp. 1449-1456. http://dx.doi.org/10.1016/j.foodchem.2006.10.061

[22] M. R. Hubbard, "Statistical Quality Control for the Food Industry,” Van Nostrand Reinhold Press, New York, 1990. http://dx.doi.org/10.1007/978-1-4757-1197-4

[23] O. Talaz, I. Gülçin, S. Göksu and N. Saracoglu, "Antioxidant Activity of 5,10-Dihydroindeno[1,2-b]indoles Containing Substituents on Dihydroindeno Part," Bioorganic \& Medicinal Chemistry, Vol. 17, No. 18, 2009, pp. 65836589. http://dx.doi.org/10.1016/j.bmc.2009.07.077

[24] S. Karakaya, S. N. El, N. Karagozlu and S. Sahin, “Antioxidant and Antimicrobial Activities of Essential Oils Obtained from Oregano (Origanum vulgare ssp. hirtum) by Using Different Extraction Methods,” Journal of Medicinal Food, Vol. 14, No. 6, 2011, pp. 645-652. http://dx.doi.org/10.1089/jmf.2010.0098

[25] A. Ünver, D. Arslan, M. M. Özcan and M. Akbulut, "Phenolic Content and Antioxidant Activity of Some Spices," World Applied Sciences Journal, Vol. 6, No. 3, 2009, pp. 373-377.

[26] B. Shan, Y. Cai, J. D. Brooks and H. Corke, "The in Vitro Antibacterial Activity of Dietary Spice and Medicinal Herb Extracts," International Journal of Food Microbiology, Vol. 117, No. 1, 2007, pp. 112-119. http://dx.doi.org/10.1016/j.ijfoodmicro.2007.03.003

[27] W. Brand-Williams, M. E. Cuvelier and C. Berset, "Use of a Free Radical Method to Evaluate Antioxidant Activity,” Lebensmittel-Wissenschaft \& Technologie, Vol. 28, No. 1, 1995, pp. 25-30.

[28] I. Hinneburg, H. J. Damien Dorman and R. Hiltunen, "Antioxidant Activities of Extracts from Selected Culinary Herbs and Spices,” Food Chemistry, Vol. 97, No. 1, 2006, pp. 122-129. http://dx.doi.org/10.1016/j.foodchem.2005.03.028

[29] T. A. Misharina and A. N. Polshkov, “Antioxidant Properties of Essential Oils: Autoxidation of Essential Oils from Laurel and Fennel and of Their Mixtures with Essential Oil from Coriander," Applied Biochemistry and Microbiology, Vol. 41, No. 6, 2005, pp. 610-618. http://dx.doi.org/10.1007/s10438-005-0111-8

[30] O. Politeo, M. Juki and M. Milo, "Chemical Composition and Antioxidant Activity of Free Volatile Aglycones from Laurel (Laurus nobilis L.) Compared to Its Essential Oil,” Croatica Chemica Acta, Vol. 80, No. 1, 2007, pp. 121126.

[31] S. Sahin, G. Sumnu, E. Yener, S. Karakaya, S. N. El and N. Karagozlu, "Extraction of Essential Oils from Spices Using Novel Technologies and Physical Antioxidant and Antimicrobial Properties of These Oils,” TUBITAK (The Scientific and Technological Research Council of Turkey), Ankara, 2009, Project Number 104 O 265. http://www.tubitak.gov.tr/

[32] A. Simic, D. Sokovic, M. Ristic, S. Grujic-Jovanovic, J. Vukojevic and P. D. Marin, "The Chemical Composition of Some Lauraceae Essential Oils and Their Antifungal Activities,” Phytotherapy Research, Vol. 18, No. 9, 2004, pp. 713-717. http://dx.doi.org/10.1002/ptr.1516

[33] H. Derwich, Z. Benziane and A. Boukir, "Chemical Composition and Antibacterial Activity of Leaves Essential Oil of Laurus nobilis from Morocco,” Australian Journal of Basic and Applied Sciences, Vol. 3, No. 4, 2009, pp. 3818-3824.

[34] O. O. Okoh, A. P. Sadimenko and A. J. Afolayan, “Comparative Evaluation of the Antibacterial Activities of the Essential Oils of Rosmarinus officinalis L. Obtained by Hydrodistillation and Solvent Free Microwave Extraction Methods,” Food Chemistry, Vol. 120, No. 1, 2010, pp. 308-312. http://dx.doi.org/10.1016/j.foodchem.2009.09.084

[35] M. Muñoz, L. Guevaral, A. Palop, J. Tabera and P. S. Fernández, "Determination of the Effect of Plant Essen- 
tial Oils Obtained by Supercritical Fluid Extraction on the Growth and Viability of Listeria Monocytogenes in Broth and Food System Using Flow Cytometry," LWT-Food Science and Technology, Vol. 42, No. 1, 2009, pp. 220227.

[36] O. Sağdiç, A. Kuşçu, M. Özcan and S. Özçelik, "Effects of Turkish Spice Extracts at Various Concentrations on the Growth of Esherichia coli 0157:H7,” Food Microbiology, Vol. 19, No. 5, 2002, pp. 473-480. http://dx.doi.org/10.1006/fmic.2002.0494

[37] O. Sağdıç, "Sensitivity of Four Pathogenic Bacteria to Turkish Thyme and Oregano Hydrosols," LebensmittelWissenschaft \& Technologie, Vol. 36, No. 5, 2003, pp. 467-473.
[38] I. Dadalioglu and G. A. Evrendilek, "Chemical Compositions and Antibacterial Effects of Essential Oils of Turkish Oregano, Bay Laurel, Spanish Lavender, and Fennel and Common Foodborne Pathogens,” Journal of Agricultural and Food Chemistry, Vol. 52, No. 26, 2004, pp. 8255-8260. http://dx.doi.org/10.1021/jf049033e

[39] M. Özcan and O. Erkmen, "Antimicrobial Activity of the Essential Oils of Turkish Plant Spices,” European Food Research and Technology, Vol. 212, No. 6, 2001, pp. 658660. http://dx.doi.org/10.1007/s002170100310

[40] O. Sağdıç and M. Özcan, "Antibacterial Activity of Turkish Spice Hydrosols,” Food Control, Vol. 14, No. 3, 2003, pp. 141-143.

http://dx.doi.org/10.1016/S0956-7135(02)00057-9 